\title{
Introduction: Special Issue on Biological Air Treatment
}

\section{Michèle Heitz}

Department of Chemical and Biotechnological Engineering, Faculty of Engineering, Université de Sherbrooke, Sherbrooke, QC

\section{Ryszard Brzezinski}

Department of Biology, Faculty of Science, Université de Sherbrooke, Sherbrooke, QC

\section{Paul Lessard}

Department of Civil Engineering, Faculty of Science and Engineering, Université Laval, Québec City, QC
We are currently witnessing a progressive deterioration in air quality due to airborne pollutants, each more harmful than the next: particulate matter, volatile organic compounds (VOCs), volatile inorganic compounds (VICs), greenhouse gases (GHGs), and so on. Not only do these emissions pose a risk to human health, but some in particular are also directly linked to the problem of climate change. The United Nations Framework Convention on Climate Change recently reiterated the potential link between global warming and the tropical storm that wreaked havoc on the Philippines in September 2009. All of this forms the backdrop to the conference entitled Traitement biologique de l'air: enjeux et perspectives ("The biological treatment of air: issues and perspectives"), held under the auspices of the 76e Congrès de l'Association Francophone pour le Savoir (ACFAS) from 5-9 May 2008 in Quebec City, Quebec, Canada. The conference was organized by Professor Michè le Heitz of the Department of Chemical and Biotechnical Engineering (GCGB) at the Université de Sherbrooke (UdeS), in tandem with her colleague Ryszard Brzezinski (Department of Biology, UdeS) and with the assistance of two GCGB PhD students, Matthieu Girard and Josiane Nikiema. Drawing on two main areas of research (engineering and life sciences), with a particular focus on the physicochemical and biological aspects of the biotreatment of air, the multi-sectoral colloquium brought together Frenchspeaking experts from Mexico, France, Spain and Canada. Topics included specific problems related to the remediation of air polluted by VOCs, VICs and (or) GHGs; global issues and related perspectives were also discussed. Biofiltration, a three-phase, complex biological process that uses microorganisms to destroy excess airborne pollutants, was a key conference topic. While biofiltration research has been ongoing for decades (the first biofilters were used during World War I to deodorize the trenches!) and applied on an industrial scale worldwide to control various industrial odours and pollutants, technological barriers continue to hamper our understanding of and ability to improve the process. In recent years, we have noted the emergence of new approaches around the world. At a biological level, the study of microbial communities would appear to be gaining ground at the expense of individual approaches that address one species or group. In terms of engineering, international research is focused on fungal, anaerobic or thermophilic bioreactors, as well as on two-liquid phase bioreactors used to treat components with low solubility in water. Lastly, it should be underscored that close collaboration between engineers and biologists is critical to advancing the understanding of air treatment bioprocesses and improving the existing approaches. The current issue of the Canadian Journal of Civil Engineering features a number of papers from the ACFAS conference.

The articles in this special issue broach the following topics: (a) biofiltration, in terms of its biological aspects (art. 3), engineeringrelated aspects (art. 2 and 9), methane treatment (art. 4 and 10), methanol treatment (art. 5), and modelling the biotreatment of hexane (art. 6); and (b) bioscrubbers for mixed volatile organic compounds (VOCs) (art. 7), bioaerosols (art. 1) and the catalytic destruction of VOCs (art. 8).

To conclude, we would like to thank the authors, co-authors and critics of these articles for their dedication to producing an exceptional issue. We would also like to thank the Université de Sherbrooke, its Department of Chemical and Biotechnological Engineering and Faculty of Engineering; the Centre de Recherche industrielle du Québec; and the ACFAS, whose financial support made the conference possible. We are likewise indebted to the Natural Sciences and Engineering Research Council of Canada, which has funded Professor Heitz's research in the field of biological treatment of air for many years. Last but not least, our thanks go to the Canadian Journal of Civil Engineering for consenting to publish a special issue on air remediation. 